\title{
SÃO COSME E DAMIÃO, CARNAVAL E SEMANA DA CRIANÇA: OLHARES E VOZES DAS CRIANÇAS EM REGISTROS FOTOGRÁFICOS ${ }^{1}$
}

\author{
Ana Cristina Coll Delgado ${ }^{2}$ \\ Rachel Freitas Pereira ${ }^{3}$
}

\section{Resumo}

Nesse artigo apresentamos uma pesquisa com crianças que focalizou a participação infantil em festas populares e datas comemorativas. Analisamos os olhares e vozes das crianças acerca das festas de São Cosme e São Damião, Carnaval e Semana da Criança. No estudo da problemática dialogamos com a sociologia da infância e com outras áreas das ciências humanas. O material empírico constituiu-se de anotações em diários de campo, entrevistas e fotografias produzidas pelas crianças. A análise com base nas fotografias e nos comentários das crianças possibilitou selecionar as principais categorias que denominamos "composições fotográficas das crianças". São elas: as ações e comportamentos dos adultos nas festas e na pesquisa, ações que envolvem consumo, diversão, brinquedos e brincadeiras e a participação das crianças nas festas e na pesquisa. As fotografias e vozes das crianças expressam as diferenças de suas histórias pessoais, das suas culturas e experiências e relações com seus contextos.

\footnotetext{
${ }^{1}$ A pesquisa contou com apoio de quatro colaboradoras de iniciação científica: Ana Paula Grellt Ferraz (Bolsista PIBIC - CNPq), Priscila Aizawa, Rachel Freitas Pereira (Bolsista FAPERGS) e Vanessa Martins da Silva (Bolsista PIBIC - CNPq). Agradecemos especialmente às crianças e a seus familiares, à professora Patrícia e toda a equipe da Escola Infantil Municipal.

${ }^{2}$ Doutorado em Educação pela Universidade Federal Fluminense/UFF e Doutorado Sanduíche pelo Instituto de Estudos da Criança, Universidade do Minho, Portugal/Braga. Mestrado em Educação pela Universidade Federal de Santa Catarina/UFSC. Especialização em Ensino pela Universidade Federal de Pelotas/UFP. Graduação em Pedagogia pela Universidade Federal de Pelotas. Atualmente é professora (grau adjunto) da Fundação Universidade Federal do Rio Grande/FURG, atuando no curso de Pedagogia e Mestrado em Educação Ambiental.

${ }^{3}$ Mestrado em Educação pela Universidade Federal do Rio Grande do Sul/UFRGS. Especialização em Orientação Educacional pela FACVEST - Faculdades Integradas da Rede de Ensino Univest. Graduação em Pedagogia - Educação Infantil e Ensino Médio pela Universidade Federal do Rio Grande/FURG. Trabalhou como bolsista de Iniciação Científica FAPERGS. É integrante do Núcleo de Estudo e Pesquisa em Educação de Crianças de Zero a Seis anos/NEPE na Universidade Federal do Rio Grande/FURG.
} 
Percebemos o quanto sua participação nas festas foi facilitada ou inibida pelas condições econômicas e sociais, pelas ideologias, pelo nível de desenvolvimento social e o bem-estar delas próprias e de seus familiares.

Palavras-chave: Crianças; infância; festas; composições fotográficas.

\section{O tema da pesquisa e uma metodologia com crianças}

Nesse texto apresentamos questões teóricas e metodológicas de uma pesquisa com crianças. A problemática central da pesquisa foi analisar como as crianças de uma escola infantil percebem sua participação em festas populares e datas comemorativas, e como interferem ou modificam esses festejos. Focalizaremos nossas análises nos olhares e vozes das crianças acerca das festas de São Cosme e Damião, Carnaval e Semana da Criança.

Como algumas festas e datas comemorativas são escolhidas e comemoradas nas escolas infantis, enquanto outras são preteridas. Almejamos compreender os sentidos das festas para as crianças, partindo das suas culturas e pontos de vista em diferentes contextos (casa, rua e escola infantil). No estudo da problemática dialogamos com a sociologia da infância e com outras áreas das ciências humanas ${ }^{4}$.

Entendemos que as manifestações culturais das crianças são construídas conjuntamente com outras vozes e culturas dos seus pares e adultos, em diferentes contextos. Os significados, simbolismos e valores que elas atribuem as festas, bem como as diversas formas de participação e protagonismo que elas exercem nos festejos mobilizou essa investigação.

\footnotetext{
${ }^{4}$ Antropologia, cultura visual, educação, filosofia, história, literatura e sociologia.
} 
Conforme estudo recente acerca dos Referenciais Curriculares Nacionais para a Educação Infantil (Schueler \& Delgado, 2008), entendemos que algumas práticas culturais, como as festas e rituais de celebração, são selecionadas ou silenciadas, conforme as complexas relações de poder/saber que interferem na construção dos currículos e das práticas nas escolas infantis.

Nesse sentido, há festas e datas comemorativas de determinados grupos que são valorizadas e oficializadas nos calendários das escolas infantis, enquanto outras são silenciadas, conforme as crianças que participaram da pesquisa nos contaram, desenharam e fotografaram.

Como as crianças se expressam de modos diferentes dos adultos, nosso desafio foi acreditar nas suas informações, ao invés de perguntar somente aos adultos o que eles pensam, ou supõem que elas pensam, sobre as festas e datas comemorativas (Graue \& Walsh, 2003). O tema da participação das crianças nas festividades é algo significativo e desafiador, provavelmente porque faz parte da história da humanidade e das nossas histórias pessoais.

Itani (2003) argumenta que as festas são como uma ação simbólica e elas podem conter nas suas comemorações muitas facetas, e como um rito, elas reúnem religião e arte, sagrado e profano, o teatro e a vida literária.

A Igreja Católica apropriou-se das celebrações pagãs, por meio de um processo de dessacralização e esvaziamento do conteúdo das festas e de substituição pelas datas religiosas (Itani, 2003). Todas estas medidas fizeram parte das políticas moralizadoras da cristandade européia. Mas, como observa Itani, muitas das festas interditadas se mantiveram, o que reforça que as festas também são práticas coletivas de resistência, como parte da história e memória de certos povos e de variados grupos sociais. 
No Brasil, a criação de datas comemorativas e as festas religiosas e populares com a participação das crianças são mediadas pela religião católica, pelo civismo, cultivo de valores morais, consumo, adultocentrismo e controle da população. Mas, por outro lado, há um contraste entre diversas tradições culturais na sociedade brasileira que, mesmo com uma forte influência do catolicismo nas festas religiosas, apresenta uma mestiçagem cultural, com ritos e manifestações culturais híbridas, como por exemplo, na força das religiões de afro-descendentes, como a Umbanda (Schueler, Delgado, \& Müller, 2007).

Nas festas e rituais as crianças têm modos de vida e compreensões do mundo, pois elas se organizam em culturas infantis (Sarmento, 2004). As culturas das crianças também apresentam fissuras internas, hibridismos (Hall, 2006), processos de mestiçagem (Gruzinski, 2001), apropriações diversas e conflitos inerentes às experiências e condicionamentos sociais de sujeitos históricos plurais (Schueler \& Delgado, 2008). Para Canclini (1998, 2005), os processos de hibridação se relacionam com a desigualdade entre as culturas, entre grupos e classes diferentes e com as assimetrias de poder e prestígio, superando a ingenuidade das visões amáveis de mestiçagem.

Como as crianças que vivem num mesmo bairro não partilham necessariamente das mesmas experiências, tradições, condições de existência e representações do mundo, as festas e as tradições culturais não podem ser sintetizadas como expressões homogêneas, e partilhadas por todos os indivíduos e grupos sociais de uma região (Schueler \& Delgado, 2008).

O entrecruzamento de culturas, raças e costumes caracteriza as festividades em nosso país e a "cultura popular emerge como resistência dos que interiorizam, reproduzem e transformam a cultura dominante, assim como a recusam implícita ou 
explicitamente" (Chauí, 1993, p. 62 - 63). No trânsito entre as culturas infantis, cultura popular e cultura de massa se produzem algumas festividades contemporâneas com a participação das crianças.

Com base nessas reflexões, percebemos as crianças como atores sociais que contribuem para criar e transmitir, através das outras gerações, as festividades. Mediante as suas práticas, seus códigos e linguagens, elas constituem as suas culturas infantis e estas marcam e transformam as festas comemorativas nas escolas, nas moradias e nas ruas. Igualmente, elas utilizam a imaginação na interpretação da realidade, com uma capacidade simbólica e criativa, transformando rituais, práticas e significados das festas e manifestações culturais tradicionais (Schueler \& Delgado, 2008).

Por compreendermos as crianças como atores sociais, esta pesquisa foi construída com elas e utilizamos os seguintes instrumentos metodológicos: observação participante com notas em diários de campo, entrevistas conversadas nas suas casas e na escola infantil, desenhos e fotografias das crianças.

Iniciamos os acordos na escola infantil e uma professora disponibilizou sua turma de maternal, na época com 15 crianças de três a quatro anos. Realizamos variados acordos com as crianças e seus familiares, antes de iniciarmos a pesquisa. Para as crianças e familiares apresentamos um documento com informações sobre a investigação e seus objetivos, explicando que as crianças são parte do processo e que é importante contar com sua participação (Mayall, 2005; Roberts, 2005).

Nos encontros iniciais oferecemos às crianças uma variedade de materiais e solicitamos que elas produzissem um desenho sobre suas festas preferidas. Após esta produção, algumas questões sobre os desenhos foram propostas para as crianças em entrevistas conversadas. 
Terminada a primeira etapa da pesquisa apresentamos os resultados para as crianças e seus familiares, propondo nossa próxima etapa metodológica, que foi o registro fotográfico dos olhares e impressões das crianças sobre as festas de São Cosme e Damião, Carnaval e Semana da Criança ${ }^{5}$.

Geralmente, cada criança recebia uma câmara para registrar as imagens das festas, porém nem todas participaram do processo com a mesma regularidade. Após estes registros conversamos sobre as fotografias, nas suas casas e na escola infantil, com gravação das conversas e anotações em diários de campo. Depois das conversas, entregamos para cada criança cópias das fotografias de sua autoria.

Foi realizada um ensaio fotográfico de uma festa junina na escola infantil (esta festa não será tema de análise nesse texto). O que mobilizou o grupo nessa primeira experiência foi apoderar-se da máquina digital e participar de uma experiência geralmente controlada pelos adultos. A acolhida positiva das crianças com relação ao uso das câmaras fotográficas ${ }^{6}$ tem relação com o interesse delas pelas novas mídias, especialmente pelas tecnologias visuais (Hernández, 2007) e também porque muitos grupos familiares têm câmaras em casa e costumam fotografar festas e comemorações das crianças pequenas.

Segundo Sontag (2004), as câmaras acompanham a vida das famílias que constroem uma crônica visual de si mesmas. Num dos seus ensaios sobre fotografia, a autora comenta que um estudo sociológico feito na França mostrou que a maioria das casas tem uma câmara, mas as casas em que há crianças têm uma probabilidade duas vezes maior de ter pelo menos uma, em comparação com as casas sem crianças. Isto

\footnotetext{
${ }^{5} \mathrm{~A}$ escolha destas festas para o registro fotográfico foi realizada após análise do material de campo coletado. A Semana da Criança foi escolhida porque é uma comemoração que ocupa uma semana ou um mês na Escola Infantil e no Município.

${ }^{6}$ Utilizamos as seguintes máquinas fotográficas: uma câmara digital YASHICA- MY 300 Kyocera, 3.1 Mega Pixels - 8x Digital zoom; uma câmara analógica YASHICA - EZ Mate Data - Kyocera; quatro câmaras analógicas YASHICA - MF. 30, e filmes de 12, 24 e 30 poses, da marca Fujifilm ISO 200.
} 
porque não tirar fotos dos filhos pequenos é sinal de indiferença paterna. Conforme constatamos em algumas visitas nas casas das crianças, mostrar as fotografias da família é algo prestigiado não só pelos adultos, como também pelas crianças.

\begin{abstract}
Dirigimo-nos à casa de Sadan, que participou da primeira etapa da pesquisa. Perguntamos se ele gostaria de participar da etapa das fotografias. Ele estava jogando na frente do computador e ficou indeciso, pois estava atento ao jogo. Seи irmão mais velho pediu que ele mostrasse suas fotos no parque de diversões. Sadan buscou os arquivos no computador. Seu pai saiu de dentro do quarto, nos cumprimentou e pediu que ele mostrasse outras fotografias. Rapidamente ele buscou o arquivo das fotos, e ainda mostrou um vídeo ligando o som do computador ao rádio. Quando fomos explicar o uso da câmara analógica, o pai de Sadan foi testá-la e percebeu que o flash não estava funcionando. Em função disso, ele não queria ficar com a nossa máquina, pois possuía uma máquina digital, e Sadan sabia utilizá-la (Registro em diário de campo).
\end{abstract}

De acordo com Pais (2006), as fotografias são imagens que não tornam visível o invisível, mas que nos convidam a ver aquilo que habitualmente não vemos. Concordando com este autor, entendemos que as crianças se apropriam de uma forma de ver o mundo através das suas imagens captadas como a realidade dos seus modos de olhar, olhares que são formas de conhecimento.

No que diz respeito ao uso das câmaras e outros meios visuais nas metodologias com crianças, Christensen e James (2005) salientam que eles entusiasmam e interessam as crianças. Porém, estes meios não podem ser utilizados como técnicas isoladas, pois os comentários das crianças sobre fotografias, quando combinados com outros métodos, como a observação participante, podem permitir a exploração de determinados assuntos com maior profundidade e fornecer uma espécie de triangulação metodológica.

\title{
Análise dos resultados
}

Optamos por uma análise das formas de linguagem que agregam o verbal ao nãoverbal, ou seja, priorizamos as vozes das crianças captadas nas entrevistas conversadas e nas anotações de campo, mas também seus olhares e impressões registrados pelas câmaras fotográficas. 
Esta análise com base nas fotografias e nos comentários das crianças possibilitou selecionar as principais categorias que denominamos 'temas de interesse das crianças'. Inspiramo-nos no estudo de Danic (2006), pois esta socióloga da infância apresenta contribuições significativas sobre a análise dos discursos e registros fotográficos, numa pesquisa com crianças. As categorias retidas foram aquelas que as crianças utilizaram para descrever suas fotos. Não houve uma hierarquização das fotos e nossas perguntas possibilitaram que as crianças fossem falando sobre suas fotos preferidas, das fotos que não gostaram, sobre o que elas apreciam nas festas e o que não apreciam. A partir dessas questões deixamos fluir as conversas e fomos problematizando seus comentários.

O material empírico foi assim estruturado: (1) anotações em diários de campo; (2) entrevistas conversadas e realização de desenhos nas casas das crianças com a presença de um ou mais familiares; (3) entrevistas conversadas com desenhos na escola infantil (criança acompanhada de um amigo); (4) fotografias produzidas pelas crianças das festas de São Cosme e Damião, Carnaval e Semana da Criança; (5) entrevistas conversadas sobre as fotografias produzidas pelas crianças nas suas casas ou na escola infantil.

O total de fotografias produzidas pelas crianças foi de 167, assim distribuídas: 20 fotografias da Festa Junina (ensaio fotográfico), 60 fotografias da Festa de São Cosme e Damião, 18 fotografias do Carnaval e 69 fotografias da Semana da Criança. Fizemos nove entrevistas conversadas com fotografias na escola infantil e nas casas das crianças, totalizando cerca de 25 horas $^{7}$.

O principal material de análise foi composto pelo corpus produzido a partir dos itens 2, 3, 4 e 5. Os diários de campo são auxiliares, ajudando na contextualização e interpretação das produções das crianças. Porém, priorizaremos nesse texto, as análises

\footnotetext{
${ }^{7}$ Durante a primeira etapa fizemos dezesseis entrevistas conversadas com os desenhos na Escola Infantil e nas casas das crianças, totalizando cerca de 30 horas.
} 
dos itens 1, 4 e 5. Alguns pontos importantes que nos auxiliaram a organizar parte dos resultados da investigação estão baseados na investigação de Danic (2006):

a) as questões espontâneas das crianças revelaram seus temas de interesse extraídos a partir do número de vezes em que mais apareceram nas entrevistas conversadas com fotografias, pela observação das fotografias e anotações de campo.

b) esta metodologia permite reduzir o efeito de imposição engendrado pelas questões do pesquisador, pois elas não estão predefinidas e se adaptam as propostas das crianças. $\mathrm{O}$ importante foi valorizar as experiências das crianças e seus pontos de vista.

c) fotografar não é registrar passivamente as festas, mas lhes perceber, lhes descobrir. Esta produção fotográfica é apreendida como manifestação dos olhares das crianças sobre as festas, tornando perceptíveis os elementos que mais retém sua atenção e suscitam seu interesse. A análise consistiu em categorizar o corpus obtido a partir de certas características, medindo a freqüência de seu aparecimento (temas de interesse mais comentados).

d) um postulado importante desse método é a freqüência de ocorrência de uma característica (tema, termo, idéia). Este trabalho de categorização do corpus se realiza pela construção de uma grelha temática após a leitura das fotos e das entrevistas. Elaboramos as categorias visando a não deformar ou trair a categorização perceptível nos temas das crianças. Numeramos as fotos no verso e nas entrevistas e associamos os comentários das crianças com as fotografias numeradas, o que facilitou a análise e as marcações dos principais temas de interesse.

A partir das entrevistas conversada, das fotografias, da análise complementar dos diários de campo e das observações das fotografias de Leão e Gabriel (ambos não 
quiseram participar das conversas nas suas casas) extraímos os seguintes temas de interesse ${ }^{8}$ mais freqüentes entre as crianças:

A) adultos e seus comportamentos nas festas; B) ações que envolvem trabalho ou descanso, brincadeiras, danças, comidas ou consumo; C) amigos/as, desafetos ou outras crianças; D) carros alegóricos; E) ela mesma (a criança fotografada por outros); F) estética das fotos, e os autores das fotografias; G) familiares; H) justificativas como: porque sim, porque não, porque gosto; I) lugares; K) medos, conflitos, situações desagradáveis; L) natureza (animais, plantas, céu, sol, lago...); M) objetos, brinquedos; N) outros adultos; O) personagens, bonecos, fantasias.

Fizemos uma contagem aproximada de quantas vezes às crianças mencionaram seus temas de interesse em cada uma das festas e os classificamos de acordo com o número de freqüência em que foram citados, sempre acompanhando as fotografias, as entrevistas conversadas e os diários de campo.

\section{Festas comemoradas pelas crianças, mas silenciadas na escola da infância}

Nos primeiros contatos nas casas das crianças, pudemos perceber a força de algumas festas populares, principalmente o Dia de São Cosme e Damião e o Carnaval (de rua, bailes infantis).

Entre as crianças, as fotografias são uma seleção daquilo que elas consideram importante para ser registrado. Suas imagens são apropriações da realidade e interpretações de momentos significativos para elas, registros que têm a mesma validade de um texto escrito.

Sontag (2004) define as fotografias como códigos visuais que modificam e ampliam nossas ideias sobre o que vale a pena olhar e sobre o que temos o direito de

\footnotetext{
${ }^{8}$ Os temas de interesse foram organizados em ordem alfabética e, posteriormente, serão apresentados seguindo a ordem de contagem e frequêencia do material empírico.
} 
observar. Elas constituem uma gramática e uma ética do ver. O resultado mais extraordinário da atividade fotográfica é nos dar a sensação de que podemos reter o mundo inteiro em nossa cabeça - como uma antologia de imagens.

As festas vividas em diferentes contextos indicam que as crianças participam de comemorações que não gozam de tanto prestígio social e cultural quanto aquelas oficializadas pelo calendário escolar. Hernández (2007) permite entendermos as festas oficializadas como uma narrativa que tem uma visão do 'nós' e dos 'outros' determinada pela hegemonia do homem branco, cristão e ocidental. Esta narrativa projeta-se na seleção de alguns conhecimentos escolares na qual o 'outro' (aquele que não faz parte do 'nós' hegemônico) é apresentado em posição de subordinação - pela qual há de ser civilizado, explorado e despojado de seus saberes.

Na escola, Júlia levantou-se da cadeira com as mãos na cabeça e disse em voz alta: Ai, ai, ai!. A professora perguntou: O que foi Júlia? O que é isso? Júlia respondeu: Estou com dor de cabeça! Ontem eu bati lá no terreiro! A professora falou em voz baixa: Que horror! (Registro em diário de campo).

\section{São Cosme e Damião: uma festa em que adultos se tornam crianças}

Um ponto forte destacado pelas crianças que participaram dos festejos de São Cosme e Damião foi o papel dos adultos, uma vez que eles incorporam entidades que se comportam como crianças, pois tomam mamadeira, usam chupetas, comem doces, engatinham e brincam.

Júlia, Antônia Brilha, Dedé, Roberta e Gabriel frequentam terreiros de Umbanda e outras igrejas (Gabriel fotografou as festas de São Cosme e Damião e da Igreja Universal), o que evidencia o sincretismo cultural das crianças e seus familiares. $\mathrm{O}$ estudo de Caputo e Passos (2007) sobre cultura e conhecimento em terreiros de candomblé demonstra que as crianças podem ser iniciadas muito cedo nos terreiros, algumas com menos de dois anos. As crianças têm um papel ativo e crescem entre os 
orixás, podendo receber cargos na hierarquia do culto. É o tempo de iniciado que conta e as crianças devem respeitar os mais velhos, mas também são respeitadas por eles. Nos terreiros pesquisados pelas autoras, quando um adulto chega para aprender a religião, uma criança já iniciada pode lhe passar os ensinamentos, ou na roda de candomblé pode se colocar na frente e puxar a roda se tiver mais tempo de iniciada. As autoras interpretam esta relação com a infância como diferente das relações adultocêntricas presentes na sociedade ocidental.

Questionamos porque as comemorações de São Cosme e Damião não fazem parte do calendário da educação infantil, uma vez que há crianças que participam desses festejos também dedicados às crianças e à infância. Lembramos que a Lei 10.639, sancionada em 9 de janeiro de 2003, determina a obrigatoriedade do ensino de História e Arte Afro-Brasileira em todos os segmentos da educação, desde a Educação Básica ao Ensino Superior (Schueler \& Delgado, 2008).

A festa de São Cosme e Damião acontece em 27 de setembro e, de forma mais sincrética, envolve católicos, umbandistas, candomblesistas e pessoas sem identidade confessional de todas as classes sociais. É uma festa das crianças, sempre com distribuição de balas, brinquedos e outros doces que é feita no interior dos terreiros, nas portas dos templos, nas ruas, nas residências, em salões de festas de prédios, em orfanatos e creches. Cosme e Damião são santos dos mais populares no Brasil, sendo venerados como os protetores das crianças e padroeiros dos médicos e farmacêuticos (Delgado, Müller \& Schueler, 2006).

Na conversa com Antônia Brilha e sua parentela, adultos e crianças associaram os festejos de São Cosme e Damião com consumo, mídia e presentes. Nesta família ganhar presentes e guloseimas pode ser propiciado por outras pessoas, algumas identificadas como pagadores de promessas: 
Na Casa de Antônia Brilha: Mãe: Eu fui com ela à festa de São Cosme e Damião. Eles distribuem doces para as crianças, tem gente que faz promessa e dá balas para 70 ou 100 crianças. Pesquisadora: E na escola tem? Mãe: Não. O vizinho ali da frente, seu Luís, esse ano é capaz dele fazer uma baita de uma festa. Ele dá todo ano as coisas para as crianças, é bolo, doce. Pesquisadora: E o que vocês fazem na festa de São Cosme e Damião? Wagner (irmão de Antônia Brilha): A gente brinca....jogam bala, jogam pirulito...tem baianas que jogam balas para cima... quem pegar é seu...(Registro em diário de campo)

Num total de 60 fotografias, apresentamos os temas de interesse mais frequientes na Festa de São Cosme e Damião, para Roberta, Júlia, Antônia Brilha, Dedé e Gabriel.

\title{
1) Outros adultos
}

Vários comentários foram feitos acerca dos adultos fotografados nesta festa. Júlia: Não estou sabendo! Tá de costas (...). O mesmo foi observado entre outras crianças como Dedé: Essa é das pessoas. Antônia Brilha: Quem é? (Registro em diário de campo).

\section{2) Os adultos e seus comportamentos nas festas}

\begin{abstract}
Na foto da 'Mariazinha', nome da entidade incorporada por uma mulher, Roberta observou: Ela é pequeninha e também chupa mamadeira. Júlia: São estes. Gostei dos bebezinhos e tudo. Pesquisadora pergunta se ela havia gostado de mais alguma coisa e Júlia respondeu: Dos Cosmes, eles são tão legais. Tomam mamadeira. Dedé: Aqui eu tirei e as mulheres me atrapalhando. Pesquisadora: E por que elas te atrapalharam? Dedé: Elas ficaram na minha frente. Antônia Brilha olhou as fotos e apontava para a 'mulher chupando bico' que aparecia em algumas das fotos. Pesquisadora pergunta se ela sabia o porquê que a mulher estava chupando bico e ela respondeu: Eu gostei dessa foto, é uma moça, ela é mulher e chupa bico, porque sim (Registro em diário de campo).
\end{abstract}

Os comentários das crianças encontram expressão nas reflexões de Barthes (1984), isso é isso, é tal! mas não diz nada mais; uma foto não pode ser transformada. Mostre suas fotos a alguém: essa pessoa logo mostrará as dela: olhe, este é meu irmão; aqui sou eu criança; a fotografia é sempre apenas um canto alternado de 'olhem', 'olhe', 'eis aqui'; ela aponta com um dedo um certo vis-à-vis e não pode sair dessa pura linguagem dêictica.

Nas imagens capturadas pelas crianças, em que os adultos estão em transe e incorporam entidades identificadas como crianças, os sentimentos e as sensações 
etéreas, (Andrade, 2002) revelados nas suas fotografias, provavelmente não expressariam a força das suas experiências e capacidade de observação num texto escrito. As crianças fotografaram rituais, danças e arquétipos porque costumam participar de Centros de Umbanda. Elas vivenciam e representam um universo social, muitas vezes desconhecido das escolas infantis.

\title{
3) A estética das fotos e os autores das fotografias
}

Para Sontag (2004), as fotos são experiências capturadas e fotografar é apropriar-se da coisa fotografada. Significa pôr a si mesmo em determinada relação com o mundo, semelhante ao conhecimento - e, portanto, ao poder. Percebemos como as crianças identificaram os autores das fotografias, fizeram observações sobre a estética das suas fotos e se surpreenderam com suas produções, assim como separaram suas fotos de outras crianças, quando os filmes foram partilhados. Entre os adultos, um sentimento forte foi a admiração frente às habilidades dos pequenos fotógrafos, o que indica certa desconfiança com relação à capacidade das crianças para manejar as câmaras e produzir boas fotografias.

\begin{abstract}
Na casa de Júlia: Bati direitinho as fotos. Essa aqui foi a Gabriela que bateu. Mãe: Olha a perfeição das fotos! Júlia: É tão legal as fotos! Vó: Ela sabe fotografar bem, viu? Mãe: Claro. Eu estou pasma, como pode tirar tão bem!]Na casa de Antônia Brilha: Dedé: Essa daqui foi a Mama (sua prima). Essa daqui foi a Mama, essa fui eu, também eu. Essa eu não gostei. Pesquisadora: Por quê? Dedé: Porque ela saiu errada. As pessoas ficaram na minha frente (Registro em diário de campo).
\end{abstract}

\section{4) Familiares}

As crianças produziram imagens dos familiares, geralmente figuras de referência nas festas. Os comentários se fixaram em detalhes e nas formas de participação dos familiares nos festejos de São Cosme e Damião. Alguns deles fizeram questão de aparecer nas fotografias, como o tio de Júlia:

Na casa de Roberta: Pesquisadora: Por quê gostas dessa foto? Roberta:

Porque é da Jenifer! Minha prima. Essa combina! Nessa a minha prima está 
com o dedo na boca e nessa outra não. (Roberta combinou duas fotos parecidas). A mãe de Júlia relatou que, no dia da festa, o tio da menina concedeu um tempo para que ela registrasse alguns momentos do ritual. Júlia preferiu sentar na frente para bater suas fotos. Na casa de Júlia. Júlia: Olha a minha vó aqui ó! Saiu até meu tio! Ele queria sair na foto toda hora! É o vô. O que a minha tia estava fazendo? Levando o que nas mãos? Vó: Ah, um pacote de balas para jogar prás crianças (Registro em diário de сатро).

\section{1) Medos, conflitos, situações desagradáveis}

Para algumas crianças, as festas têm outros sentidos que parecem estar além do prazer e do deleite. Sentimentos e emoções, como descontentamentos com as atitudes dos adultos, também fazem parte dos seus olhares e impressões. Algumas fotografaram suas dificuldades e conflitos com os adultos e as situações tensas vividas nas festas.

Pesquisadora perguntou para Júlia, sobre o que ela não havia gostado na festa, e ela respondeu: Daquele preto (...) tem a foto. Pesquisadora pergunta porque e ela responde: (...) eu não gosto de homem. Nem pensar! Ele se arrasta no chão e ele passa uma coisa no rosto das crianças (Júlia irritada faz o gesto, passando uma das mãos no rosto.). Aquele velhinho. Jogaram uma aguinha. Eu gostei que jogavam uma aguinha nas crianças. Júlia continuava a repetir o gesto com as mãos e dizia: Aquele hominho passou uma coisa no meu rosto. Antônia Brilha mencionou que: (...) as mulheres jogavam água na gente. Sua mãe complementou dizendo que jogavam guaraná com a mamadeira nas crianças (Registro em diário de campo).

\section{4) Justificativas como: por que sim, por que não, por que gosto?}

Em sua investigação, Danic (2006) encontrou casos de crianças que escolhem uma resposta, não sabendo verdadeiramente explicar o fundamento de sua ação, exprimindo regularmente respostas parecidas como as que encontramos: por que gosto, por que sim, por que não etc. Igualmente constatamos que, em alguns casos, parte da motivação para escolher o que fotografar não parecia consciente ou explicável para as crianças.

Estas manifestações das crianças parecem compatíveis com o que escreve Barthes (1984, p. 34): "Eu via muito bem que estavam em questão movimentos de uma subjetividade fácil, que acaba logo, assim que a exprimimos: gosto/não gosto: qual de nós não tem sua tábua interior de gostos, desgostos, indiferenças?” 
Na escola infantil: Pesquisadora: Por que gostas dessa foto? Roberta: Por que sim. Quais são tuas fotos preferidas? Júlia apontou as de número 2, 18, 13 e 11 e complementou: Só estas. Pesquisadora: Por quê? Júlia: Porque é tão legal essas fotos. Todas eu gostei. Pesquisadora: Quais fotos preferes? Antônia Brilha: (mostrou a foto 11) por que sim (Registro em diário de campo).

\section{1) Ações que envolvem trabalho ou descanso, brincadeiras, danças, comidas ou consumo}

O prazer de estar com as pessoas, bem como o prazer sensorial vivido no momento (comer um bolo, tomar um refrigerante) aparece como uma tentativa de captar a situação em todos os seus aspectos pelas crianças. Objetos significativos para elas, ou o que eles simbolizam nas festas, também foram fotografados. Igualmente elas justificaram suas fotos pelo fato de simplesmente gostarem, ou se interessarem por algo (Danic, 2006).

Roberta: Eu tomei refrigerante e comi doce. Antônia Brilha: Na foto 1 falou: Algodão doce. Também disse que bateu as fotos de número 12 e a de número 7 que é a do bolo. Olhou para a foto número 8 e falou: Estão comendo chocolate. Gabriel chegou na sala contando que no dia anterior tinha ganhado um monte de balas e pirulitos (Registro em diário de campo).

\section{5) Objetos, brinquedos}

Na escola da infantil: Dedé: Essa. Pesquisadora: Por quê? Dedé: Por causa que tem essas coisas daqui (estava se referindo ao altar do terreiro de Umbanda) (Registro em diário de campo).

\section{6) Amigos/as, desafetos ou outras crianças}

Além dos amigos/as também aparecem os desafetos $\mathrm{e}$ as dificuldades existenciais de algumas crianças, principalmente com as do sexo oposto.

Na casa de Roberta: Roberta: A Júlia e o Braian. Pesquisadora: Tem alguma que te desagradou? Roberta: Essa. A do Matheus. E por quê?? Roberta: Porque ele estragou minha bicicleta (Registro em diário de campo)..

\section{7) Ela mesma (a criança fotografada por outros)}


Na casa de Júlia: Júlia: Aquela hora eu não queria sair na foto (Registro em diário de campo.

Nem sempre ser fotografada pelos pares ou adultos foi algo prazeroso para as crianças. Possivelmente os familiares pediram que as crianças se deixassem fotografar para guardar uma lembrança. Em vários conjuntos de fotografias observamos que as crianças foram fotografadas sozinhas, ou acompanhadas de amigos, pais, mães, avós ou tios.

\section{Carnaval não é só diversão: trabalho, descanso, medos e brincadeiras nas impressões das crianças}

Não foi possível ignorar a importância da conjuntura social, econômica e política e as condições materiais de existência e bem-estar das crianças e suas famílias. Especialmente no ano da festa de carnaval analisada, percebemos as dificuldades vividas pelas crianças, pois apenas Leão e Roberta conseguiram participar dos festejos. As mudanças constantes de endereço em função da instabilidade de algumas famílias, as desigualdades sociais e dilemas contemporâneos são indicadores das possibilidades ou limitações de participação das crianças nas festas de rua.

$\mathrm{Na}$ primeira etapa da pesquisa, Leão, Viviane, Roberta, Henrique e Antônia Brilha demonstraram que o carnaval de rua e os bailes infantis são festas importantes para as crianças e seus familiares.

$\mathrm{Na}$ casa de Leão, após um tempo de conversa observamos que ele havia separado uma máscara de plástico, nas cores branco e preto, do filme Pânico 2. Num dado momento da conversa, Leão colocou a máscara no rosto e relatou suas experiências com o carnaval de rua e com um baile de carnaval infantil.

Leão: Eu coloquei a máscara e brinquei com ela. Pesquisadora: Que músicas as crianças apreciam no baile infantil? Leão: Timbalelê da Xuxa. Foi o primeiro baile de carnaval infantil de Leão e ele contou que abanou para outro menino que estava de máscara. Leão disse gostar de carro alegórico, que sua festa preferida é o carnaval da avenida, pois lá tem bonecos grandes (Registro em diário de campo). 
Quando perguntamos para Antônia Brilha sobre qual é sua festa preferida ela respondeu que é a festa da Colombo e a princípio não entendemos. Depois ela fez um comentário sobre dois bonecos grandes e sobre uma pessoa que tinha levantado a saia da boneca. Isto nos fez pensar no desfile de blocos burlescos que acontece na Rua Cristóvão Colombo nas noites de carnaval (Registro em diário de Campo).

O consumo e o papel da mídia ocupam um papel importante no carnaval e este apelo atinge as crianças e suas famílias, pelas fantasias, canções (marchinhas da Xuxa e outras veiculadas pela mídia), comidas, bebidas e ingressos cobrados nos bailes infantis e nos desfiles do sambódromo.

Frente às dificuldades vividas pelas crianças (na família de Antônia Brilha o pai estava preso, e a mãe, desempregada e grávida, contava somente com bolsa-família), ainda existe a possibilidade de um membro da parentela, ou um vizinho, acompanhar as crianças nos festejos.

Na casa de Antônia Brilha: Pesquisadora: Quais são tuas festas preferidas? Antônia Brilha: Carnaval da Colombo. (Nesse momento entreguei o gravador para a mãe de Antônia Brilha conduzir a conversa.). Mãe: O que tu gostas de ver no carnaval, minha filha? Antônia Brilha: A boneca da fantasia. Mãe: De qual música tu gostas? Antônia Brilha: A música da cuca. Mãe: O que tu vistes por lá? Antônia Brilha: Boneco, boneca. Mãe: Antônia Brilha, minha filha, de qual bloco que tu gostas? Antônia Brilha: Da Colombo. Mãe: Onde tua dinda te levou? Antônia Brilha: No bloco da Marilú (Registro em diário de campo).

As máscaras, fantasias, canções e fotografias de outros carnavais foram elementos importantes nas entrevistas. A conversa na casa de Leão se tornou mais animada, quando ele colocou a máscara, sambou e lembrou das suas experiências com a avó carnavalesca. O carnaval caracteriza-se como uma festa que procura canalizar as tensões, os desejos e a loucura, e as máscaras sempre representaram uma manifestação popular contra a instituição social vigente (Bakhtin, 1993).

No Brasil, o carnaval mantém a característica de ser uma festa de rua, que ocorre no verão. Nosso carnaval, com variadas características e especificidades regionais, é um evento internacionalmente conhecido e há mais de um século exportado como símbolo 
de uma suposta identidade nacional, em que pesem as diferenças e as pluralidades de significados que os festejos carnavalescos adquirem nas diferentes localidades, para os diferentes sujeitos, festeiros de origens étnicas, culturais, religiosas, sociais, idades e referências identitárias extremamente complexas e heterogêneas (Delgado, Müller \& Schueler, 2006).

O carnaval faz parte da tradição cultural das crianças e seus grupos familiares, porém várias delas não puderam vivenciar esta etapa da pesquisa. Júlia não fotografou o carnaval porque seu pai ficou desempregado nesse período; Sadan foi a um baile infantil e sua mãe alegou ter esquecido a câmara; Barbie que Voa vivia conflitos decorrentes da separação dos pais e nunca estava no endereço de contato e a mãe de Gabriel não permitiu que ele fotografasse o Carnaval. Antônia Brilha não participou, porque sua família estava passando por grandes dificuldades.

Antônia Brilha veio correndo até o portão para nos receber. A mãe, já no final da quinta gravidez veio andando devagar. Ela perguntou se tínhamos assistido na TV, que seu marido havia sido baleado em dezembro pela polícia. Ele ficou 17 dias no hospital e depois voltou para o presídio. O pai de Antônia Brilha estava envolvido com tráfico de drogas (Registro em diário de campo).

Apenas Roberta e Leão fotografaram o Carnaval. Roberta e sua mãe receberam auxílio do presidente da Escola de Samba Império, pois são carnavalescas e desfilam nesta escola. A mãe de Leão mencionou as limitações econômicas para acompanhar o filho:

Leão tirou fotos do carnaval da Colombo e quando fomos entregar as fotos do carnaval sua mãe observou: O bom mesmo é no sambódromo, mas é três reais a entrada. Ai chega lá o guri com aquela mania de querer uma coisa. Aquele dia mesmo ele pediu uma coisa para comer e uma coisa para tomar, ele foi mais por causa disso (Registro em diário de campo).

A mãe de Roberta contou que elas desfilariam na Escola Império no sambódromo de Rio Grande. Ela perguntou se a filha poderia fotografar os ensaios que ocorriam todas as noites. Patrícia falou que nos ensaios Roberta fica perambulando, e observa as outras escolas. Procuramos entregar a máquina com 36 poses, mas infelizmente a atendente da loja 
misturou as máquinas e não percebemos o problema (Registro em diário de сатро).

Dois equívocos foram cometidos nessa etapa da pesquisa. O primeiro diz respeito à possibilidade de oferecermos uma ajuda de custo para que os familiares pudessem acompanhar seus filhos nas festas de rua ou bailes infantis, uma vez que este grupo de crianças desejava fotografar o Carnaval. O outro equívoco está relacionado com as trocas das câmaras, pois justamente Roberta que participou de ensaios da Escola Império, desfilou no sambódromo e foi a um baile infantil recebeu um filme de 24 poses, e boa parte dele queimou restando apenas oito fotografias.

Como salienta Danic (2006), dificilmente os pesquisadores expõem os bastidores de uma pesquisa, porque isto não é indispensável na apresentação dos resultados e seus erros seriam expostos. Nossas opções são decorrentes de experiências de formação e pesquisas anteriores. Entra em jogo, no processo de pesquisa, uma combinação de elementos que não podemos desprezar quando refletimos sobre nossos erros e tateamentos.

Leão não quis comentar sobre as fotografias do Carnaval e Gabriel também se recusou a conversar sobre as fotografias de São Cosme e Damião e da Festa na Igreja Universal. Principalmente nas suas casas e algumas vezes na Escola Infantil, eles pareciam intimidados pela situação de face à face. Danic (2006) explica que algumas vezes as crianças se mostram aborrecidas frente ao pesquisador: se elas não ousam deixar abruptamente o entrevistador, elas sabem exprimir seu aborrecimento e encurtar a situação cessando toda cooperação (sinais de impaciência, gritos, respostas fantasiosas sem levar em conta a questão). Para exemplificar: Leão ficou assistindo a um desenho na TV e ignorou nossa presença. Gabriel nos recebeu no portão, mas ficou brincando com os primos e não quis comentar sobre suas fotografias. Em ambos os casos fomos 
bem recebidos pelos seus familiares que se surpreenderam com suas produções. A maioria das crianças apreciou conversar sobre as fotografias e algumas prolongaram a entrevista, como Roberta.

Num total de 18 fotos do carnaval encontramos os seguintes temas de interesse entre Leão (pela observação das suas fotografias) e Roberta:

\section{1) Ações que envolvem trabalho ou descanso, brincadeiras, comidas ou consumo}

Na casa de Roberta: Pesquisadora: E o que essas pessoas estavam fazendo? Roberta: Estavam trabalhando. Eu tava brincando porque eu tinha levado a minha boneca grandona. Pesquisadora: E por que gostas dessa? Roberta: Porque tem dois anjinhos e uma escadinha. Pesquisadora: E ali tem pessoas. Elas estavam fazendo o quê? Roberta: Estavam cansadas de trabalhar. (fotografou algumas pessoas descansando) Pesquisadora: Tu saberias me dizer do que as crianças mais gostam no carnaval? Roberta: Elas gostam de ir ali na rua, gostam de brincar na rede que tinha lá, e gostam de subir nos carros, e gostam de ver os carros. Pesquisadora: Tem mais alguma coisa que as crianças gostam no carnaval? Roberta: Gostam de sambar. Também gostam de descansar na rede. Pesquisadora: Tinha uma rede lá? Roberta: É. A Julie gosta de brincar comigo de estátua, mas tem que ser na rede, eu sou a estátua e ela a pegadora. Roberta: Brincam... Eu gosto de brincar na rede. Só que uma vez eu já caí da rede bem alta. Machuquei a cabeça. (Risos). Pesquisadora: Tem mais alguma coisa que as crianças tenham gostado no carnaval? Roberta: Não... Elas gostam também de ficar trabalhando. Eu fiquei uma vez pintando uma tampinha. Pesquisadora: E no baile? Roberta: Háaaaa! Nós dançamos com a mãe da Natália! Eu tenho outras fotos sobre essas, mas não são... (as fotos do baile queimaram) (Registro em diário de campo).

As reflexões de Roberta, acerca dos ensaios de escolas de samba, nos indicam um outro lado do carnaval, cujas imagens falam e nos surpreendem. Como reflete Barthes (1984), no fundo, a fotografia é subversiva, não quando aterroriza, perturba ou mesmo estigmatiza, mas quando é pensativa.

Roberta que vive os ensaios da escola de samba e desfila na Império, sabe que para ela e outras crianças o carnaval não é só diversão. Embora elas brinquem em meio às fantasias e carros alegóricos, os ensaios e preparativos para o desfile envolvem trabalho, descanso e conflitos. As relações entre infância e trabalho constituem-se em categorias sociológicas problematizadoras das representações arbitrárias e, muitas 
vezes, idealizadas dos adultos com relação aos grupos infantis. Tais representações não traduzem os mundos reais vividos pelas crianças, que trabalham e participam tanto simbolicamente, quanto materialmente, na transformação e na manutenção das relações sociais. Estas são teses defendidas por Qvortrup (2001) que entende as crianças como engajadas na produção econômica e no consumo.

\section{1) Personagens, bonecos e fantasias}

Na casa de Roberta: Roberta: A Iemanjá. Pesquisadora: E por que tu gostas dessa? Roberta: Porque ela era bem grande. E também bonita. Ela tem um cabelão (Registro em diário de campo).

\section{2) Carros alegóricos}

Na casa de Roberta: Roberta: É aqui é do carnaval que eu já fui. Tem a do Tigre também. Esse aqui é o tigre. Essa aqui é da Iemanjá. Esse aqui é aquele da casinha. Esse aqui é aquele de girar. Essa daqui... (Registro em diário de campo).

\section{3) Outros adultos}

Na casa de Roberta: Roberta: É. Essa aqui é a minha professora e o presidente. É... E também tem essa aqui... (Olha atrás da foto que contém os negativos, e inventa um número, já que eu olhava os números das fotos) É a zero três... O presidente... (Aponta para uma das fotos do negativo. Olha e compara.) É essas daqui são grandes (Registro em diário de campo).

\section{4) Os adultos e seus comportamentos nas festas}

Na casa de Roberta: Pesquisadora: E do que os adultos não gostam? Roberta: Eles não gostam, que a gente toque na tinta que eles pintam. Também tem o que eles mais gostam que é que ajude a trabalhar né mãe?... Porque eu já trabalhei com eles. Também tem um amigo da mãe, que nem me lembro como é o nome dele... (Registro em diário de campo).

\section{5) Medos, conflitos, situações desagradáveis}

Na casa de Roberta: Roberta: A gente gosta de brincar de esconder. Tinha um bonecão, também tem as bonecas... Não, as bonecas não... A gente anda se escondendo do bonecão. (Risos) Ele faz prá cima e prá baixo, prá cima e prá baixo, e a gente se assustava (Registro em diário de campo).

Analisando a entrevista de Roberta sobre o carnaval, constatamos que ela, como carnavalesca, não está do lado de fora da experiência, pois vive e faz parte dos ensaios, preparativos e desfiles. Ela é capaz de refletir sobre seus sentimentos fazendo um 
movimento de autoconhecimento através dos outros. Por descrever com pormenores suas experiências e os sentimentos que os adultos e crianças lhes despertam, Roberta é capaz de enxergar com olhos de lince e olhos de alma (Andrade, 2002).

Mesmo frente ao problema das fotos queimadas do baile infantil, Roberta encontrou soluções criativas: mostrou sua fantasia, cantou um trecho do samba enredo da sua escola e apresentou fotografias dos anos anteriores para complementar a entrevista. Isto demonstra que as noções de tempo das crianças não obedecem a uma cronologia linear. Danic (2006) também observa que a narração das crianças não respeita uma cronologia dos acontecimentos, conforme os adultos esperam.

Na casa de Roberta: Roberta: Cadê mesmo mãe? Mãe: Não sei, não saiu. As fotos queimaram. Roberta: Não mãe! (Um pouco irritada) As fotos aquelas que eu já vi, e que tão ali em cima. Mãe: Há! As fotos de outros carnavais, quando tu eras pequenininha! Roberta: Te lembras? (Me mostra as fotos da festa de São Cosme e Damião e as fotos da festa da Semana da criança) Roberta: Esse é o que estragou a minha bicicleta, até hoje estou furiosa com ele. Pesquisadora: Essas são as fotos de São Cosme né? Roberta: É. Olha a Mariazinha! Ela mora lá perto da casa da minha dinda... olha meu amigo! Mãe: Esse carroceiro... Conta pra ela o que ele fazia filha! Roberta: Ele me dava fruta. A Pipoca. O nome de verdade dela é Pamela. (Continua me mostrando todas as fotos da festa do dia da criança) Roberta: Tá tudo misturado (Registro em diário de campo).

\section{A semana da criança: uma comemoração planejada pelos adultos}

Os festejos da Semana da Criança são amplamente comemorados na escola infantil e em eventos promovidos no município de Rio Grande ${ }^{9}$. Mais do que 'O dia da Criança', os festejos ocupam uma semana ou um mês, com ampla divulgação no comércio, na mídia e na organização de festas em variados espaços. As programações são diversificadas e há uma série de atividades que envolvem guloseimas, presentes, gincanas passeios e atrações. Contraditoriamente, esta comemoração dedicada à infância geralmente é planejada e pensada pelos adultos, o que reflete o controle e a

\footnotetext{
${ }^{9}$ No Brasil, a iniciativa de criar um dia especialmente dedicado às crianças ocorreu em 1920. Depois de aprovado, o 12 de outubro foi oficializado como dia da criança para ter lugar em todo o território nacional (Delgado, Müller \& Schueler, 2006).
} 
regulação de uma festa que é das crianças, mas que somente pode ser vivida mediante a presença, vigilância e organização dos adultos.

Para Hernández (2007), uma forma de narrativa poderosa no terreno educativo é aquela que tende à naturalização; as coisas são como são e não podem ser pensadas de outra maneira. Entendemos que no caso das festas e datas comemorativas há uma forte naturalização na seleção do que é digno de reconhecimento e celebração. Na 'Semana da Criança' é forte o adultocentrismo e a naturalização dos modos de pensar a infância, como se as crianças não fossem capazes de fazer escolhas e julgamentos. As crianças não decidiram com os adultos as formas de comemoração, embora a maioria delas tenha apreciado os passeios e atividades de recreação.

Curioso é que profissionais da educação que criticam as influências da mídia e do consumo nas vidas das crianças reforçam este poder em festas como o 'Dia da Criança', Natal e Páscoa, datas em que o apelo ao consumo infantil é especialmente incentivado.

Num total de 69 fotos produzidas pelas crianças nos eventos promovidos pela escola infantil, na apresentação de Roberta e seus familiares em outra escola infantil e na Festa da Igreja Universal fotografada por Gabriel, os temas de interesse mais frequientes foram:

\section{1) A natureza (animais, plantas, céu, sol, lago...)}

Nossas análises e concepções das crianças como membros de uma família, e principalmente interessadas pelos brinquedos, jogos e brincadeiras são, no mínimo, dignas de questionamento, pois suas fotografias e comentários revelam que elas pensam e refletem sobre seus mundos culturais, assim como estão atentas ao meio ambiente. 
Mesmo que as crianças não tenham sido as protagonistas do planejamento da

'Semana da Criança', elas participaram ativamente das comemorações, bem como refletiram e manifestaram suas opiniões. Pinto (2002) enfatiza a necessidade de olharmos as crianças como agentes com capacidade reflexiva e, conscientes, em determinado grau, das condições e conseqüências da sua ação. O passeio ao Museu Oceanográfico é um exemplo do quanto foi significativo para elas registrar imagens da natureza, do ambiente e dos animais.

Cristian perguntou se poderia tirar uma foto dos ossos da baleia. Antônia Brilha pediu a máquina: Quero tirar foto do pinguim'. Barbie que Voa também pediu a máquina para tirar fotos do leão marinho. Cristian tirou fotos do 'médico dos pingüins'. Dedé pediu a máquina para bater fotos do leão marinho. Antônia Brilha pediu a máquina para tirar fotos dos peixes e das tartarugas do lago: Me dá a máquina. Eu quero tirar foto do peixe. Leão pediu para tirar fotos do peixe com óculos e da motoca de andar no gelo. Foram as únicas fotos que ele quis bater. Ao longo do passeio, as crianças foram tirando fotos do que queriam e ultrapassaram o que havia sido estabelecido. Eu não sabia muito bem como agir, pois a toda hora queriam a máquina. Elas ficaram encantadas com um lago artificial com vários pássaros se banhando (Registro em diário de campo).

Colocamos as fotos sobre a mesa, e logo Cristian começou a olhar. Barbie que Voa, em um primeiro momento, apenas observava o que Cristian comentava sobre as fotos. São cavalos marinhos. Ossos da baleia. Os pingüins. Há! A aguinha dos passarinhos. Perguntei se havia alguma que ele não tivesse gostado muito, e ele mostrou a número 28 e falou: Essa não, não é de bichinho. Perguntamos para Barbie que Voa de quais fotos ela havia gostado e ela escolheu as fotos número: 16. Muito legal essa! Passarinhos porque eu gosto. Marinho: Tartarugas que vimos no museu. Ela continuou a olhar as fotografias restantes sobre a mesa e perguntou para nós se sabíamos onde estava a foto do osso. Nós a ajudamos a encontrar e ela falou: $O$ osso da baleia. Citou também como suas fotos preferidas as de número: 03. Eu tava pegando sol e por isso tava de olho fechado. Foi do peixinho. Perguntamos se tinha alguma que ela não havia gostado. Ela olhou novamente as fotos sobre a mesa e pegou nas mãos a de número 37. Não gostei, porque não tinha bichinho. Não gostei da foto dos passarinhos, porque não vi nada, só sujeira. Fomos chamar Dedé para conversar. Eu tirei do bicho, quase peguei o bicho (referindo-se ao leão marinho). Dá pra ver a cabeça do bicho só um pouquinho. Dos passarinhos e da tartaruga, fui eu que bati. Perguntamos sobre sua foto preferida e ele apontou a 46. Porque tem um negócio, o cavalinho e o mar (Registro em diário de campo).

Na escola: Antônia Brilha: Aqui é o pingüim. Barbie que Voa: O osso da baleia. Priscila: O que tem nessa foto? Antônia Brilha: Era uma coisa que se atira na água. Pesquisadora: Era o leão marinho? Antônia Brilha: A comida que davam era peixe. Mais um osso da baleia. Antônia Brilha:

Revista Reflexão e Ação, Santa Cruz do Sul, v.18, n2, p.29-64, jul./dez. 2010 
Tinha uma tartaruga na água. Os passarinhos iam beber água. Eu gostei dos pingüins. Priscila: Por quê? Antônia Brilha: Porque é bonito! (Registro em diário de campo).

\title{
2) Ações que envolvem trabalho ou descanso, brincadeiras, danças, comidas ou consumo
}

\begin{abstract}
Na casa de Roberta: Roberta espalhou as fotos em cima da cama e falou: Vou arrumar as fotos, está muito bagunçado. Eu ganhei um carrinho no dia das crianças e duas bonecas. A mãe, eu, a Julie, a mana e a minha dinda estamos vestidas de bonequinha. Porque tinha uma festa no colégio do Braian. O Braian roubou uma bolinha do colégio da Julie daquelas piscininhas. Pesquisadora: E o que vocês fizeram lá na festa? Roberta: Brincamos de desfilar, brincamos daquela coisa de pular assim, das bolinhas. Brincamos de pular corda com as crianças. Mãe: Como tu te apresentasse filha? Roberta: A mãe me ligou e eu dancei (Registro em diário de campo).
\end{abstract}

Perguntei se eles sabiam que esta é a semana em comemoração ao dia da criança. Barbie que Voa falou que sabia, e que iria ganhar uma Barbie de presente. Gabriel falou que iria ganhar um carro bem grandão (Registro em diário de campo).

Antônia Brilha comentou com sua professora, Patrícia: Ganhei aquele DVD de por DVD. Patrícia perguntou de quem e ela respondeu: Do Beto, meu avô. Saindo dali fomos para o pátio, onde foram montadas a cama elástica e a piscina de bolinhas. As crianças tiveram que fazer uma fila, e esperar sua vez para brincar. Eram três crianças de cada vez e ficavam em torno de cinco minutos em cada brinquedo. As crianças estavam impacientes e irritadas na fila, algumas gritavam: Eu quero subir. Leão foi o único que não quis bater fotos, as outras crianças bateram. As crianças maiores queriam passar na frente dos menores. Depois de certo tempo, as crianças não queriam bater fotos, mas olhar as outras crianças brincarem. Depois que entravam na cama para pular, não queriam sair. Na sala, Patrícia encheu alguns balões e colocou um suporte de plástico em cada balão. Júlia viu e falou que nunca tinha visto balão preso em um canudinho e falou no meu ouvido: É prá nós levar para casa. Realmente, após o almoço Patrícia deu um balão para cada criança (Registro em diário de campo).

Na escola: Cristian: A gente brincando. Barbie que Voa: As crianças no colchão. Antônia Brilha: E aqui é a cama elástica. Júlia: Gostei da cama elástica também (Registro em diário de campo).

As representações de infância presentes nas comemorações da 'Semana da Criança' estão associadas com diversão, consumo e prazer. Embora as crianças que participaram da pesquisa tenham comentado ou registrado seus desejos de consumir 
brinquedos e diversões, como se vivessem um período de inocência e pureza, a maioria delas enfrentava dificuldades de toda ordem.

Alguns estudiosos da infância como Kincheloe (1997); Pinto (2002) e Sarmento (2004) têm observado que nas sociedades contemporâneas o mercado está mais atento aos modos de vida das crianças que hoje não estão ausentes das relações econômicas e são consumidoras em potencial.

Para Sarmento (2004), uma das características da contemporaneidade é o efeito homogeneizador do processo de globalização, com o investimento do marketing e da publicidade destinados ao público infantil.

Na contemporaneidade observa-se uma indústria de serviços criados para as crianças. Esta indústria cultural influencia os festejos da 'Semana da Criança', com os brinquedos criados para espaços fechados (cama elástica e piscina de bolinhas), balões, jogos, brinquedos, roupas, filmes, entre outros. Como explica Sarmento (2004), a norma da infância tende também a exprimir-se na invasão dos cotidianos infantis de todo o mundo pela poderosa indústria de produtos para a infância, embora nem todas consigam realizar seus desejos de consumo.

\section{3) A estética das fotos e os autores das fotografias}

Quando as crianças não gostam das fotografias, geralmente suas justificativas estão associadas ao que elas concebem como belo e feio, incluindo desde pequenos detalhes, até os adultos que atrapalharam seus registros. Para Sontag (2004), o que move as pessoas a tirar fotos é descobrir algo belo e ninguém exclama: Como isso é feio! Tenho de fotografá-lo. Mesmo se alguém o dissesse, significaria o seguinte: Acho essa coisa feia...bela.

Na casa de Roberta: Olha aqui, saiu um pedacinho do vestido da minha mãe. (Olha todas as fotos) Essas eu não gostei. Pesquisadora: Por quê? 
Roberta: Porque não. Essa tá diferente, tem lacinho só aqui. Tiraram o lacinho dela (Risos) (Registro em diário de campo).

Na escola infantil: Dedé: Não gostei. Saiu errado, porque as pessoas ficavam na frente. Foi o Leão. Fui eu. Fui eu. Não fui eu. Fui eu que bati. Só as do museu que eu bati. Ficou todo errado, é aqui do lado. Foi a Mama. Barbie que Voa: Eu não gostei dessas coisinhas que têm aqui (Registro em diário de campo).

\section{4) Amigos/as, desafetos ou outras crianças}

Na casa de Roberta: Roberta: A Julie. Pesquisadora: E quem é? Roberta: É minha amiga: Eu gostei dessa. Porque ela é minha amiga. Pesquisadora: E estas? Roberta: Porque são minhas amigas. Só que essa é a minha mana e essa é minha amiga. Antes eu não gostava dela, agora eu gosto. Pesquisadora: E por que tu não gostavas dela? Roberta: Porque ela puxava o meu pé e puxava o meu cabelo (Registro em diário de campo).

Na Escola Infantil: Cristian: Leão, o cabeçudo. Gustavo: Irmão da Letícia. Leão: A amiga da outra sala. Júlia: A Antônia Brilha está aqui? Barbie que Voa: Vem cá Antônia Brilha. Júlia: Aqui os meus colegas. Antônia Brilha: É o Vinicius, aqui é o Gustavo. Priscila: Por que esta não te agradou? Júlia: Porque eu não gosto de meninos. Eu só gosto dos meninos que são meus colegas (Registro em diário de campo).

\section{5) Familiares}

É interessante como Roberta transita entre o imaginário e a realidade com desenvoltura, quando identifica Luciele (sua madrinha) que, na festa de outra escola infantil, estava caracterizada como palhaça Pipoca e irmã da boneca que ela representou. Num momento, Roberta associou Luciele à Palhaça Pipoca e sua madrinha como uma única pessoa. Vejamos como ela faz este trânsito e ainda corrige sua mãe, mesmo utilizando a fantasia do real, como um dos modos de expressão das culturas infantis (Sarmento, 2004).

Na casa de Roberta: Roberta: A Luciele! Aqui faz de conta que ela é a Pipoca! É a palhaça Pipoca! (risos) Aqui estão todas juntas! A mãe, a dinda, a Pipoca e a Luciele. Mãe: A Luciele é irmã dela. Roberta: A minha dinda! (a mãe diz que é a irmã da boneca e ela corrige dizendo que é sua madrinha) (Registro em diário de campo).

Dedé: Mama (referindo-se a Antônia Brilha). Mama também. Meu irmãozinho,fui eu que tirei (Registro em diário de campo). 


\title{
6) Ela mesma (a criança fotografada por outros)
}

Pesquisadora: És tu nessa foto? Roberta: (Faz sinal com a cabeça que sim) Roberta: Eu e a Julie estamos de bonequinha! Cristian: Eu (Registro em diário de campo).

\section{1) Personagens, bonecos, fantasias}

\begin{abstract}
Dani entrou na sala e chamou a turma da Patrícia para ir até o salão. Chegando lá havia um cenário montado, e um bolo decorado com os personagens da história João e Maria e uma casa feita de doces. Pedi para Júlia que estava mais próxima bater uma foto do que ela estava gostando. Ela bateu somente uma foto do teatro de fantoches, pois queria prestar atenção na história (Registro em diário de campo).
\end{abstract}

Danic (2006) observa que as circunstâncias são frequentemente reportadas nas fotografias: A atividade da criança é citada, bem como a proximidade afetiva dos amigos. Geralmente aparecem as justificativas estéticas, as justificativas afetivas (porque eu gosto), mas também as justificativas imaginárias: a criança bate a foto de um lugar ou situação que lhe atrai ou que lhe dá medo.

\section{Reflexões finais: imagens fotográficas e vozes das crianças nas festas}

As fotografias e vozes das crianças expressam as diferenças de suas histórias pessoais, das suas culturas e experiências e relações com seus contextos. Poderíamos supor que as crianças comentariam sobre outras fotos em entrevistas posteriores. Mas como Danic (2006), também constatamos que as preferências estavam constantes. Alguns exemplos confirmam nossas afirmações: Roberta retomou as mesmas escolhas das fotografias de São Cosme e Damião e Semana da Criança e Leão registrou imagens do Carnaval do ano anterior a pesquisa, que foram narradas por ele na entrevista (bonecos e mascarados). 
As imagens e vozes das crianças nos surpreenderam, pois elas simplesmente apontaram seus registros, identificaram adultos, crianças, situações ou evocaram suas dificuldades, medos e gostos. Lendo Barthes (1984), compreendemos a fotografia como inclassificável, pois o que ela reproduz ao infinito só ocorreu uma vez e nunca mais poderá repetir-se existencialmente. Muitas vezes as crianças comentaram o vivido e o acontecido, mediadas pelos seus contextos sociais e culturais.

As crianças manifestaram seus desejos, prazeres, religiosidade, medos, sentimentos e impressões sobre as festas e os adultos, sobre elas mesmas, a natureza e o mundo. Seus registros fotográficos estão mediados por suas culturas e subjetividades. Elas registraram e documentaram as festas, observando o todo e os detalhes. Provavelmente, elas foram mais atraídas pela intensidade das suas experiências do que pela quantidade de fotos registradas (Hernández, 2007). A curiosidade, a inquietação e a abertura para o senso estético proporcionou uma interpretação das festas com sentimentos e imaginação. Convivemos com crianças reais, ativas, construtoras das festas, competentes e críticas para desenvolverem um pensamento reflexivo durante a investigação.

Percebemos o quanto sua participação nas festas foi facilitada ou inibida pelas condições econômicas e sociais, pelas ideologias, pelo nível de desenvolvimento social e o bem-estar delas próprias e de seus familiares. Com as crianças aprendemos um pouco mais sobre nossa cultura, nossas origens e sobre a diversidade em nosso país. Talvez nesse percurso tenhamos conhecido um pouco mais de nós mesmos (Andrade, 2002).

Metodologicamente, o recurso das fotografias apresentou uma vantagem, que foi facilitar a expressão das crianças pequenas. Concordamos com Andrade (2002), que entende as imagens como observações estéticas e documentais da realidade. 
Presenciamos estas observações estéticas entre as crianças e elas também nos ensinaram que a fotografia e a etnografia podem contribuir entre si; como os processos de observação da ciência e da arte podem completar-se e não atritar-se.

Os mundos culturais das crianças, a regulação dos adultos, a participação das crianças nos festejos e seus movimentos de resistência são indicadores de que as escolas infantis precisam incluir nas suas programações as festas e culturas silenciadas das crianças e seus familiares, o que nos parece mais justo e democrático. Mas como destaca Hernández (2007), recuperar o poder na escola, mediante a autorização e a visibilidade das vozes dos que não têm voz, é algo que deve ser realizado sem paternalismo.

\section{SAINT COME ET SAINT DAMIEN, LE CARNAVAL ET LA SEMAINE DE L"ENFANCE: DES REGARDES ET DES VOIX DES ENFANTS DANS LES DOCUKENTS PHOTOGRAPHIQUES}

\section{Resumé}

Dans cet article, nous présentons une enquête auprès des enfants qui portent sur la participation des enfants dans les fêtes populaires et les dates commémoratives. Nous avons analysé les points de vue et les voix des enfants au sujet de la fête de Saint Côme et Saint Damien, le Carnaval et la Semaine de l'enfance. Dans cet étude nous avons dialogué avec la sociologie de l'enfance et d'autres domaines des sciences humaines. Les données empiriques se composent de l'observation participante avec des notes sur le terrain et des interviews pour débattre avec les enfants sur leurs photographies. L'analyse, fondée sur les photographies et les commentaires des enfants ont permis de sélectionner les principales catégories que nous appelons "compositions photographiques des enfants." Ce sont : les actions et les comportements des adultes 
lors des fêtes et dans la recherche, les actions impliquant la consommation, les diversions, les jouets et les jeux, et la participation des enfants lors des fêtes et dans la recherche. Les photographies et les voix d'enfants expriment les différences dans leurs histoires personnelles, leur culture et leurs expériences et leurs relations avec leurs contextes. Nous avons analysé comment leur participation aux fêtes a été facilité ou inhibé par des conditions sociales et économiques, par des idéologies, par le niveau de développement social et leur bien-être et celui de leurs familles.

Mots-clés: Efants; enfance; fêtes, compositions, photograpiques.

\section{Referências}

ABBAGNANO, Nicola. Dicionário de Filosofia (Tradução Alfredo Bosi). 2. ed. São Paulo: Martins Fontes, p. 841-844,1992.

ARIÈS, Philippe. A História Social da Criança e da Família. Rio de Janeiro: LTC, 1981.

ANDRÈ, Marli Eliza D. A. de. Etnografia da prática escolar. Campinas (SP): Papirus, 1995. (Série Prática Pedagógica)

AZANHA, José Mário Pires. Uma ideia de pesquisa educacional. São Paulo: Edusp/Fapesp, 1992.

BARBOSA, Silvia Neli Falcão; KRAMER, Sônia; SILVA, Juliana Pereira. Questões teórico-metodológicas da pesquisa com crianças. In: Perspectiva. Revista do Centro de Ciências da Educação. V 23, Janeiro/Junho, Florianópolis: 2005.

BROUGÈRE, Gilles. Brinquedo e cultura. São Paulo: Cortez, 1995.

BRASIL, Lei de Diretrizes e Bases da Educação Nacional. Lei 9394/96, de 20 de Dezembro de 1996. Brasília/DF: MEC, 1996.

BRASIL. Lei $\mathbf{n}^{\mathbf{0}}$ 10.639/2003. Dispõe sobre a obrigatoriedade do ensino de História e Cultura Afro-Brasileira. Disponível em www.senado.gov.br (acesso em 10 de janeiro de 2008).

CAPUTO, Stela Guedes; PASSOS, Mailsa. Cultura e conhecimento em terreiros de candomblé - lendo e conversando com mãe Beata de Yemonjá. Currículo sem Fronteiras, v.7, n.2, pp.93-111, jul/dez 2007. 
CHRISTENSEN, Pia; JAMES, Allison.(orgs) Investigação com crianças. Perspectivas e práticas. Escola Superior de Educação de Paula. Porto, Franssinetti, 2005.

COHN, C. (2005). Antropologia da Criança. Rio de Janeiro: Jorge Zahar.

CORSARO, Willian. Entrada no campo, aceitação e natureza da participação nos estudos etnográficos com crianças pequenas. Revista Educação \& Sociedade. CEDES ,Vol 26 - Mai./Ag. 2008. p.443 a 464.

CORSARO William A. Acção colectiva e agência nas culturas de pares de crianças pequenas. Department of Sociology, Indiana University, Bloomington USA, 1997 (mimeo).

CORSARO William A. A reprodução interpretativa no brincar ao "faz-de-conta" das crianças. Educação, Sociedade e Culturas, Porto, n.17, p.113 - 134, 2002.

DELGADO, Ana C. \& MULLER, Fernanda. Sociologia da Infância: pesquisas com crianças. IN: Educação \& Sociedade: Revista de Ciência da Educação. Vol. 26, mai/ago. São Paulo: Cortez, 2005.

DAHLBERG, Gunilla, MOSS, Peter e PENCE, Alan. Qualidade na Educação da Primeira Infância: perspectivas pós-modernas. Porto Alegre: Artmed, 2003.

FERREIRA, Aurélio Buarque de Holanda. Novo Dicionário Aurélio Século XXI: o dicionário da língua portuguesa. 3 ed. Rio de Janeiro: Nova Fronteira, 1999.

FARIA, Ana Lúcia; DEMARTINI, Zélia B. F; PRADO, Patrícia Dias (Orgs). Por uma cultura da infância: metodologias de pesquisa com crianças. Campinas/SP. Editora Associados, 2002.

FERREIRA, Maria Manuela Martinho. A Gente Aqui o que Gosta mais é de Brincar com os Outros Meninos: as crianças como actores sociais e a (re)organização social do grupo de pares no quotidiano de um Jardim de Infância. Porto, 2002. Dissertação (Doutoramento em Ciências da Educação). Faculdade de Psicologia e Ciências da Educação, Universidade do Porto.

FERREIRA, Maria Manuela Martinho. Do "avesso" do brincar ou... as relações entre pares, as rotinas da cultura infantil e a construção da(s) ordem(ens) social(ais) instituintes(s) das crianças no jardim-de-infância. In: SARMENTO, Manuel Jacinto \& CERISARA, Ana Beatriz. Crianças e miúdos: perspectivas sociopedagógicas da infância e educação. Edições ASA- Porto- Portugal 2004.

FERNANDES, Florestan. As 'Trocinhas' do Bom Retiro. Folclore e Mudança Social na cidade de São Paulo. Vozes: Petrópolis, 1979.

GEERTZ, Cliffort. A Interpretação das Culturas. São Paulo: Guanabara Koogan, 1989. 
GREVERAND, G.; BARDOS, M. (2001). Do que é que você gosta? Rio de Janeiro: Salamandra.

GURAN, M. (2000). Fotografar para descobrir, fotografar para contar. Cadernos de Antropologia e Imagem. Rio de Janeiro, p. 155-165.

INSTITUTO DE ESTUDOS DA CRIANÇA DA UNIVERSIDADE DO MINHO; NÚCLEO DE ESTUDOS E PESQUISA DA EDUCAÇÃO DE 0 A 6/UFSC. Projeto de pesquisa. Crianças: educação, culturas e cidadania ativa. Florianópolis - Brasil; Braga Portugal, 2002 (mimeo).

JOBIM E SOUZA, Solange. Re-significando a psicologia do desenvolvimento: uma contribuição crítica à pesquisa da infância. In: KRAMER, Sônia, LEITE Maria Isabel. Infância: fios e desafios da pesquisa. São Paulo/Campinas: Papirus, 1996. p. 39-55.

JAMES, Allison \& PROUT, Alan. Hierarquia, Fronteira e Agência: para uma perspectiva teórica sobre a infância. In: FERREIRA, Manuela e SARMENTO, M. J. (orgs.). Antropologia de Textos em Sociologia da Infância, Porto: ASA, 2004.

JAMES, Allison; JENCKES, Chris e PROUT, Alan. Teorizing childhood. Cambridge. Polity Press, 1998.

JAMES, Allison. Investigação com Crianças. Perspectivas e Práticas. Porto: Editora Porto, 2005, p. 243 - 260.

JENCKES, Chris. Constituindo a criança. Revista Educação, Sociedade e Culturas. Edições Afrontamento, LTDA: Porto, Portugal, nº 17. p. 113-134, 2002.

KRAMER, Sônia, LEITE, Maria Isabel et al (orgs.) Infância e educação infantil. Campinas, SP: Papirus, 1999.

KRAMER, Sônia. Autoria e autorização: questões éticas na pesquisa com crianças. In: Cadernos de Pesquisa. São Paulo, nº 116, p. 41-59, jul. 2002.

KRUPSKAYA, N. K. Acerca de la educación preescolar. Havana: Editorial Pueblo y Educación, 1979.

LOPES, Ana Elisabete. Foto-grafias: as artes plásticas no contexto da escola especial. In: KRAMER, Sônia \& LEITE, Maria Isabel (Orgs.). Infância e produção cultural. Campinas, São Paulo: Papirus, 1998. p. 75-107.

LANGSTED, Ole. Avaliando a qualidade do ponto de vista das crianças. Danish SocialScience Recerch Council, 1991. Tradução Livre de Débora Thomé Sayão, revisada por Edna Duck e Brian Duck (mimeo).

LEITE, M. I. F. P. O que falam de escola e saber as crianças da área Rural? Um desafio da Pesquisa no campo. In: KRAMER, S.; LEITE, M. I. (orgs). Infância: fios e desafios da pesquisa. Campinas: Papirus. 1996. 
LIVIA, M.; ORLOV, V.. Na cauda da pipa. Coleção Marcha Criança. Editora Scipione. 2003.

LÚDKE, Menga \& ANDRÉ, Marli. Pesquisa em educação: abordagens qualitativas. São Paulo, EPU, 1996.

MÜLLER, Fernanda. Infâncias nas vozes das crianças: culturas infantis, trabalho e resistência. In: 26a . Reunião Anual da ANPED. Caxambu/MG: 2003. Texto disponível em: www.anped.org.br

MARTINS, José de Souza. (org.) Regimar e seus amigos: a criança na luta pela terra e pela vida. In: MARTINS, José de Souza. O massacre dos inocentes. São Paulo: Hucitec, 1993.

MONTANDON, C. Sociologia da Infância: balanço dos trabalhos em língua inglesa. In: Caderno de Pesquisa, nº11, FCC, São Paulo, 2001, p. 33-60.

PAUSEWANG, G. (2000). A escola dos meninos felizes. São Paulo: Loyola.

PINTO, Manuel; SARMENTO, Manuel J. As crianças. Contextos e identidades. Portugal, Centro de estudos da criança: Bezerra, 1997.

PAIS, José M. Nas rotas do quotidiano. Revista crítica de ciências sociais, n.37, junho, 1993.

PAIS, José Machado. Nos Rastos da Solidão. Deambulações Sociológicas. Porto: Âmbar, 2006.

PINTO, Manuel. A televisão no quotidiano das crianças. Educação Sociedade \& Culturas, Porto, n.17, p.226-228, 2002. Resenha do livro: PINTO, Manuel. A televisão no quotidiano das crianças. Porto: Edições Afrontamento, 2000, 400 páginas. (Conceição Ventura e Rita Cabral).

PROUT, Alan. Reconsiderar a nova Sociologia da Infância: para um estudo multidisciplinar das crianças. Ciclo de Conferências em Sociologia da Infância. 2003/2004. IEC. Tradução: Helena Antunes. Braga/Portugal: 2004 (digitalizado).

ROBERTS, Helen. Ouvindo as Crianças: e escutando-as. In: CHRISTENSEN, Pia \& JAMES, Allison. Investigação com Crianças. Porto: Perspectivas e Práticas, 2005.

SARMENTO, Manuel J. \& PINTO, Manuel. As crianças e a Infância: definindo conceitos delimitando o campo. In: PINTO, Manuel \& SARMENTO, Manuel J. (coord.) As Crianças: Contextos e Identidades. Braga, Portugal: Centro de Estudos da Criança, 1997.

SARMENTO, Manuel J. \& PINTO, Manuel.(coord.). Saberes sobre as Crianças: para uma bibliografia sobre a infância e as crianças em Portugal. Braga, Portugal: Universidade do Minho, 1999. 
SARMENTO, Manuel J.. A infância: paradigmas, correntes e perspectivas (mimeo). Florianópolis, 2002.

SARMENTO, Manuel Jacinto. Gerações e alteridade: interrogações a partir da sociologia da infância. In: Educação \& Sociedade, 2005, vol.26, n. 91.

SIROTA, Régine. Emergência de uma Sociologia da Infância: evolução do objeto e do olhar. Cadernos de Pesquisa, São Paulo, nº 112, pp.7-31, mar. 2001.

SILVA, Juliana Pereira da; BARBOSA, Silva Neli Falcão; KRAMER, Sônia. Questões teórico-metodológicas da pesquisa com crianças. Perspectiva, Florianópolis, v.23, n.01, p.41-64, jan./jul. 2005.

SOARES, Natália Fernandes. Outras infâncias... A situação social das crianças atendidas numa Comissão de Proteção de Menores. Braga, Portugal: Centro de Estudos da Criança. Universidade do Minho. 2006.

SOUZA, S. J. A Pesquisa como intervenção nas relações entre crianças e adultos no âmbito da cultura da mídia. Trabalho apresentado no XXVIII Congresso Brasileiro de Ciências da Comunicação. UERJ, 2005.

SCHUELER, Alessandra e DELGADO, Ana Cristina Coll. Os Referenciais Curriculares Nacionais para a Educação Infantil: reflexões sobre festas, história e memória em escolas infantis. II Congresso Internacional Cotidiano: Diálogos sobre Diálogos, março de 2008, Universidade Federal Fluminense, Publicação Texto Completo em CD - ROM.

SCHUELER, A. F. M., DELGADO, Ana Cristina Coll, MULlER, F. A participação das crianças nas festividades brasileiras, Educação em Questão, v.29, n.15, p. 122 148, mai/ago 2007.

SONTAG, Susan. Sobre Fotografia. São Paulo: Cia das Letras, 2004.

Data de recebimento: 10/07/2010

Data de aceite: 04/09/2010 